\title{
BMJ Global Health Ethical and policy considerations for COVID-19 vaccination modalities: delayed second dose, fractional dose, mixed vaccines
}

\author{
Jonathan Wolff (D , ${ }^{1}$ Caesar Atuire, ${ }^{2}$ Anant Bhan, ${ }^{3}$ Ezekiel Emanuel, ${ }^{4}$ Ruth Faden, ${ }^{5}$ \\ Prakash Ghimire (i) , ${ }^{6}$ Dirceu Greco, ${ }^{7}$ Calvin W L Ho (D) , ${ }^{8}$ Sonali Kochhar, ${ }^{9,10}$ \\ Surie Moon, ${ }^{11}$ Owen G Schaefer (D) , ${ }^{12}$ Ehsan Shamsi-Gooshki, ${ }^{13}$ \\ Jerome Amir Singh, ${ }^{14,15}$ Maxwell J Smith (D) , ${ }^{16}$ Beatriz Thomé, ${ }^{17}$ Aissatou Touré, ${ }^{18}$ \\ Ross Upshar ${ }^{19}$
}

To cite: Wolff J, Atuire C, Bhan $A$, et al. Ethical and policy considerations for COVID-19 vaccination modalities: delayed second dose, fractional dose, mixed vaccines. BMJ Global Health 2021;6:e005912. doi:10.1136/ bmjgh-2021-005912

Received 3 April 2021 Revised 14 April 2021 Accepted 16 April 2021
Check for updates

C Author(s) (or their employer(s)) 2021. Re-use permitted under CC BY-NC. No commercial re-use. See rights and permissions. Published by BMJ.

For numbered affiliations see end of article.

Correspondence to Professor Jonathan Wolff; jonathan.wolff@bsg.ox.ac.uk

\section{INTRODUCTION}

As a growing number of vaccines for COVID-19 gain emergency use designation, including emergency use authorisation and conditional marketing authorisation under different jurisdictions, the WHO Strategic Advisory Group of Experts on Immunization (SAGE) ${ }^{1}$ has issued a number of guidance papers for their recommended use. The overall framework is set out in an Evidence Framework document, ${ }^{2}$ and has currently been applied to several vaccines. ${ }^{3-5}$ The framework is also guided by the SAGE Values Framework ${ }^{6}$ and prioritisation guidelines. ${ }^{7}$ The overarching aim of the Evidence Framework is to make recommendations based on the principles of evidence-based medicine.

COVID-19 immunisation is a very fastmoving area, with a highly varied landscape, as new vaccines become available, yet supply lags a long way behind global demand. The emergence of new variants adds further complexity. Each country is in its own unique circumstances and while scientific knowledge is increasing day by day, there are many scientific uncertainties, and few easy decisions. Even taking current scientific knowledge into account, very often decisions involve trade-offs with health and non-health risks and benefits on both sides, calling for judgements to be made by policymakers. It is not the aim of this paper to provide a solution to the very difficult questions different countries face, but to provide guidance on the considerations that ethically should be taken into account in making such decisions about whether to proceed with different modalities.
Summary box

A number of countries are considering administering COVID-19 vaccines in ways that have not been informed by clinical trials, nor recommended by the manufacturers or authoritative international health bodies, in order to provide some protection for a greater number of people under conditions of vaccine scarcity, or for other reasons.

- Proposals include delaying the second dose of twodose vaccines beyond the period for which there is evidence from clinical trials, or foregoing it entirely, giving fractional doses, providing vaccines for individuals outside recommended age ranges, or providing different vaccines for the first and second, or booster, doses.

- The WHO Strategic Advisory Group of Experts on Immunization Values Framework provides a valuable ethical background for considering the policy questions concerning choice of vaccine modalities, highlighting that vaccines are a global public good for the benefit of all, and drawing on values of human well-being, equal respect, global and national equity, reciprocity and legitimacy.

- This paper considers the factors that we believe governments have an ethical duty to take into account in considering the vaccination modality they adopt.

- In developing their policies, governments must take seriously the evolving scientific evidence base, as well as potential effects on public trust, the legitimate expectations and rights of those who have been begun the vaccination process, responsibility to the global community and equity, among others considersations, and to communicate their reasons for their decisions appropriately to the affected populations.

- Any decision to adopt a modality that differs from those recommended by manufacturers must be accompanied by comprehensive and clear mechanisms to follow-up those in alternative modalities. 
By 'different modalities' we mean proposals for administering vaccines in ways that have not been recommended by the manufacturer, or approved by authoritative international bodies such as WHO, or supported by strong emerging evidence, but are being considered in the search for the best overall set of public policies to bring the pandemic under control.

\section{MODALITIES UNDER CONSIDERATION}

Although various further modalities may appear, we are aware that a number of modalities are under discussion or actually implemented:

1. Delaying the second dose of two-dose vaccines beyond the period supported by clinical trial data, in order to give more people some immediate protection sooner.

2. Only providing one dose of two-dose vaccines, for the same reason, especially in cases where people had previously been infected.

3. Giving fractional doses of the vaccine, for the same reason.

4. Giving the first and second doses of different vaccines to the same recipient, either because of a belief that it will confer additional protection, or when there are problems with record keeping or supply, or because of emerging concerns about the safety of the first vaccine administered.

5. Giving vaccines to populations outside the recommended age range, to increase coverage.

6. Not adjusting the vaccine interval/schedule in the light of emerging evidence; for example, not delaying the second dose when emerging data suggest a longer interval gives stronger protection.

7. Using a different vaccine to those previously administered as a booster dose.

The SAGE Values Framework ${ }^{6}$ document sets out a very helpful background against which to consider the policy questions. The key ideas, which we quote, are:

\section{Overarching goal}

COVID-19 vaccines must be a global public good. The overarching goal is for COVID-19 vaccines to contribute significantly to the equitable protection and promotion of human well-being among all people of the world.

\section{Principles}

- Human well-being. Protect and promote human well-being including health, social and economic security, human rights and civil liberties, and child development.

- Equal respect. Recognise and treat all human beings as having equal moral status and their interests as deserving of equal moral consideration.

- Global equity. Ensure equity in vaccine access and benefit globally among people living in all countries, particularly those living in low and middle-income countries.
- National equity. Ensure equity in vaccine access and benefit within countries for groups experiencing greater burdens from the COVID-19 pandemic.

- Reciprocity. Honour obligations of reciprocity to those individuals and groups within countries who bear significant additional risks and burdens of COVID-19 response for the benefit of society.

- Legitimacy. Make global decisions about vaccine allocation and national decisions about vaccine prioritisation through transparent processes that are based on shared values, best available scientific evidence, and appropriate representation and input by affected parties.

\section{CONSIDERATIONS}

In the light of these values, and in particular the values of human well-being, equal respect and legitimacy, combined with the SAGE Evidence Framework, we propose that in considering deviating from the guidance recommended by the manufacturers or authoritative international bodies such as WHO, and following a different modality, a government has obligations to:

1. Be mindful that its responsibilities extend beyond the residents of its country but also to the global community, and that any decisions it takes about vaccine administration in its own country can have global implications, especially in relation to the conditions under which variants of concern are more likely to emerge.

2. Pay close attention to the latest scientific evidence, including WHO guidance, concerning both the safety and effectiveness of the policies it adopts, and recognise that safety, efficacy and effectiveness give rise to very different concerns. While acknowledging that scientific findings are always subject to uncertainty and change, governments must consider the best available empirical evidence regarding the following risks, and should continue to monitor all relevant emerging evidence concerning:

a. The immunity level for the individual likely to be achieved by the modality under consideration, compared with the recommended modality, both in terms of strength and duration.

b. The immunity level for the community likely to be achieved by the modality under consideration, compared with the recommended modality, both in terms of strength and duration.

c. The overall national effect on death, hospitalisation, severe disease and infection rates likely to be achieved by the modality under consideration, compared with the recommended modality.

d. Whether some subpopulations, with lower risk of severe disease or death, are more suitable for the modality under consideration.

e. Whether the modality under consideration will pose an additional risk of adverse effects for individuals vaccinated. 
f. Whether the modality under consideration will pose an additional risk of virus mutation, or conversely lower such risk by increasing the number of people with some immunity.

g. Whether the modality under consideration, especially when administered against manufacturer's explicit recommendations, or other authoritative guidance, will increase vaccine hesitancy.

h. The longer term health, economic and social consequences of following the recommended modality if the consequence is that it takes longer to bring infections to a low level.

3. Consider whether the modality under consideration will invalidate vaccine indemnification provisions.

4. Consider whether variation in modalities between countries, or within countries with a federal structure, will lead to a loss of confidence in public health authorities.

5. Consider the legitimate expectations of those who were initially vaccinated on the understanding that they would receive the second dose within a certain time frame; whether there are obligations to those who formed such expectations; and whether the urgency of the situation, or the benefits of any change, justifies over-riding any such obligations; and to consider new forms of consent that may become appropriate as the vaccine programme rolls out.

6. Consult with, and where practicable involve, independent health and medical bodies, national ethics committees, and religious and civil society organisations and groups, and to respond to concerns that emerge in a timely, transparent and appropriate manner.

7. Clearly, accurately and widely communicate the nature of the policy and the reasons for it.

8. Carefully keep under surveillance, and where possible actively research, the effects of the modality used, and keep policy under regular review in light of all information received, and share all pertinent information with the international community. Such monitoring should not be limited only to scientific information, but public perceptions and behaviour should also be evaluated and taken into account.

9. Ensure that the implementation of any modality does not breach principles of equity, by, for example, increasing risk to disadvantaged populations and minorities.

10. Do not treat policy considerations as in themselves sufficient reason to neglect scientific evidence, but rather combine policy considerations and scientific evidence to inform a complex process of deliberation.

\section{CONCLUSION}

There is no fixed and easy formula for balancing these risks and other factors, and each government must make its own judgement. However, we strongly recommend that each government carefully considers the issues we have set out here, and any others that become relevant especially in its own particular circumstances, in collaboration with all interested stakeholders, to the degree that this is possible. We believe that a government will be failing in its duties to its residents and the broader global community if it proceeds without carefully balancing all relevant considerations.

\section{Author affiliations}

${ }^{1}$ Blavatnik School of Government, Oxford University, Oxford, UK

${ }^{2}$ Philosophy and Classics, University of Ghana, Accra, Greater Accra, Ghana

${ }^{3}$ Centre for Ethics, Yenepoya University, Mangalore, Karnataka, India

${ }^{4}$ Department of Medical Ethics and Health Policy in the Perelman School of Medicine, University of Pennsylvania, Philadelphia, Pennsylvania, USA

${ }^{5}$ Berman Institute of Bioethics, Johns Hopkins University, Baltimore, Maryland, USA

${ }^{6}$ Department of Microbiology, Tribhuvan University, Kirtipur, Kathmandu, Nepal

${ }^{7}$ Professor Emeritus, School of Medicine, Federal University of Minas Gerais, Belo Horizonte, Minas Gerais, Brazil

${ }^{8}$ Department of Law, and Centre for Medical Ethics and Law, University of Hong Kong, Pok Fu Lam, Hong Kong

${ }^{9}$ Global Healthcare Consulting, New Delhi, India

${ }^{10}$ Department of Global Health, University of Washington, Seattle, Washington, USA

${ }^{11}$ Law, Graduate Institute of International and Development Studies, Geneve,

Switzerland

${ }^{12}$ Centre for Biomedical Ethics, Yong Loo Lin School of Medicine, National University of Singapore, Singapore

${ }^{13}$ Medical Ethics and History of Medicine Research Center, Tehran University of Medical Sciences, Tehran, Iran

${ }^{14}$ Howard College School of Law, University of KwaZulu-Natal, Durban, KwaZuluNatal, South Africa

${ }^{15}$ Division of Clinical Public Health, Dalla Lana School of Public Health, University of Toronto, Toronto, Ontario, Canada

${ }^{16}$ Preventive Medicine Department, Faculty of Health Sciences, University of

Western Ontario, London, Ontario, Canada

${ }^{17}$ Federal University of São Paulo, São Paulo, Brazil

${ }^{18}$ Indpendent consultant, Dakar, Senegal

${ }^{19}$ Dalla Lana School of Public Health, University of Toronto, Toronto, Ontario, Canada

Twitter Jonathan Wolff @jowolffBSG, Owen G Schaefer @G_Owen_Schaefer, Ehsan Shamsi-Gooshki @ehsanshamsi713 and Maxwell J Smith @maxwellsmith

Contributors The conception for this paper was a collective effort based on group discussion, with many suggestions circulated by email. The corresponding author wrote the first draft. All other authors contributed further comments and suggestions, which were discussed in at least three further group meetings. The corresponding author then wrote a second draft, which received further comments and discussion before he finalised the final draft.

Funding The authors have not declared a specific grant for this research from any funding agency in the public, commercial or not-for-profit sectors.

Competing interests None declared.

Patient consent for publication Not required.

Provenance and peer review Not commissioned; internally peer reviewed.

Data availability statement There are no data in this work.

Open access This is an open access article distributed in accordance with the Creative Commons Attribution Non Commercial (CC BY-NC 4.0) license, which permits others to distribute, remix, adapt, build upon this work noncommercially, and license their derivative works on different terms, provided the original work is properly cited, appropriate credit is given, any changes made indicated, and the use is non-commercial. See: http://creativecommons.org/ licenses/by-nc/4.0/.

\section{ORCID iDs}

Jonathan Wolff http://orcid.org/0000-0003-2608-5674

Prakash Ghimire http://orcid.org/0000-0003-2503-412X

Calvin W L Ho http://orcid.org/0000-0002-8328-1308

Owen G Schaefer http://orcid.org/0000-0002-6915-6148

Maxwell J Smith http://orcid.org/0000-0001-5230-0548 


\section{REFERENCES}

1 Strategic Advisory group of experts on immunization (SAGE). Available: https://www.who.int/groups/strategic-advisory-group-ofexperts-on-immunization/covid-19-materials

2 Evidence to recommendations for COVID-19 vaccines: evidence framework. Available: https://www.who.int/publications/i/item/WHO2019-nCoV-SAGE-Framework-Evidence-2020-1

3 Interim recommendations for use of the Moderna mRNA-1273 vaccine against COVID-19. Available: https://www.who.int/ publications/i/item/interim-recommendations-for-use-of-themoderna-mrna-1273-vaccine-against-covid-19

4 Interim recommendations for use of the Pfizer-BioNTech COVID-19 vaccine, BNT162b2, under emergency use listing. Available: https://
www.who.int/publications/i/item/WHO-2019-nCoV-vaccines-SAGE recommendation-BNT162b2-2021.1

5 Interim recommendations for use of the AZD1222 (ChAdOx1-S [recombinant]) vaccine against COVID19 developed by Oxford University and AstraZeneca: interim guidance, 2021. Available: https://apps.who.int/iris/handle/10665/339477

6 WHO. SAGE values framework for the allocation and prioritization of COVID-19 vaccination. Available: https://www.who.int/publications/ i/item/who-sage-values-framework-for-the-allocation-andprioritization-of-covid-19-vaccination

7 WHO. Sage roadmap for prioritizing uses of COVID-19 vaccines in the context of limited supply. Available: https://www.who.int/publications/ $\mathrm{m} /$ item/who-sage-roadmap-for-prioritizing-uses-of-covid-19vaccines-in-the-context-of-limited-supply 